\title{
Molecular cloning of preproinsulin cDNAs from several osteoglossomorphs and a cyprinid
}

\author{
Azza A. Al-Mahrouki a, David M. Irwin ${ }^{\text {b,c }}$, Lane C. Graham ${ }^{\text {d }}$, John H. Youson ${ }^{a, *}$ \\ ${ }^{a}$ Department of Zoology and Division of Life Sciences, University of Toronto at Scarborough, Scarborough, Ont., Canada M1C 1A4 \\ ${ }^{\mathrm{b}}$ Department of Laboratory Medicine and Pathobiology, Faculty of Medicine, University of Toronto, 101 College Street, Toronto, \\ Ont., Canada M5G 1 L5 \\ ${ }^{\mathrm{c}}$ Banting and Best Diabetes Centre, University of Toronto, 101 College Street, Toronto, Ont., Canada M5G 1L5 \\ ${ }^{\mathrm{d}}$ Department of Zoology, University of Manitoba, Winnipeg, Man., Canada R3T 2N2
}

Received 20 September 2000; accepted 13 November 2000

\begin{abstract}
Several preproinsulin cDNAs were isolated and characterized from four members of the Osteoglossomorpha (an ancient teleost group); Osteoglossum bicirrhosum (arawana), Pantodon buchholzi (butterfly fish), Notopterus chitala (feather fin knife fish), Hiodon alosoides (goldeye) and Gnathonemus petersii (elephantnose). In addition, we isolated and characterized the preproinsulin cDNA from Catostomus commersoni (white sucker, as a representative of a generalized teleost). The comparative analysis of the sequences revealed conservation of the cystine residues known to be involved in the formation of the disulfide bridges, as well as residues involved in the hexamer formation, except for B-17 in the butterfly fish, the arawana and the goldeye. However, the N-terminus of the B-chain was very weakly conserved among the species studied. Residues known to be significant for maintaining receptor-binding conformation and those known to comprise the receptor-binding domain were all conserved, except for a conservative substitution at B13, aspartate substituted glutamate in the arawana, goldeye, butterfly fish and white sucker, and at B16, phenylalanine substituted tyrosine in the elephantnose. Phylogenetic analysis of the sequences revealed a monophyletic grouping of the osteoglossomorphs, and showed that they were not the most basal living teleost. Comparative sequence analysis of preproinsulins among the osteoglossomorphs was useful in assessment of intergroup relationship, relating elephantnose with the feather fin knife fish and the arawana, butterfly fish, and goldeye. This arrangement of species is consistent with relationships based on other more classical parameters, except for the goldeye which was assessed as being sister to all the osteoglossomorphs. The white sucker was grouped with the common carp and both are cyprinids. (C) 2001 Elsevier Science Ireland Ltd. All rights reserved.
\end{abstract}

Keywords: Cyprinid; Molecular cloning; Osteoglossomorpha; Preproinsulin; Teleost

\section{Introduction}

Osteoglossomorpha is an ancient subdivision of living teleost fishes, whose ancestors originated at the late Jurassic era about 200 million years ago before the separation of the major continental areas ( $\mathrm{Li}$ and Wilson, 1996). The wide geographical distribution of the extant osteoglossomorphs make them a potential interesting group of fishes to study. Patterns of endemism were reported for the different taxa (Osteoglos-

\footnotetext{
* Corresponding author. Tel.: + 1-416-2877397; fax: + 1-4162877676.

E-mail address: youson@scar.utoronto.ca (J.H. Youson).
}

sidae, in South America; Notopteridae, in East Asia and Africa; Pantodontidae and Mormyridae in West Africa and Hiodontidae, in North America). This interesting geographical distribution illustrates the influence of the tectonic plate movements on the distribution of fresh-water organisms. (Li and Wilson, 1996). Furthermore, their relationships to other teleosts are not well resolved. Nelson (1973), Patterson and Rosen (1977), and Taverne (1986) indicated that the osteoglossomorphs are the most ancient living teleosts. This view was challenged by Arratia (1991) who suggested that there is an elopomorph-osteoglossomorph sister group relationship, which was supported by a phylogenetic analysis using 28S rRNA sequences (Van Le et al., 
1993). Recently, O'Neill et al., (1998) examined the phylogeny in ancient teleosts using gonadotropin-releasing hormones $(\mathrm{GnRH})$ molecular forms and found a close relationship between the eel (an elopomorph) and the butterfly fish (an osteoglossomorph). Several researchers agree that the Osteoglossomorpha is a monophyletic group (Li and Wilson, 1996; Zhang, 1998) and there have been several recent analysis on the inter-relationship among the osteoglossomorphs. Li et al. (1997) reported that the Notopteridae (e.g. feather fin knife fish) and Momyridae (e.g. elephantnose) are most closely related and together they are a sister-group to the Hiodontidae (e.g. goldeye). Sequence analysis of the mitochondrial 12S rRNA and 16S rRNA (AlvesGomes and Hopkins, 1997) indicated that the Pantodon (e.g. butterfly fish) departs considerably from the mormyriformes (e.g. elephantnose).

The characterization and the comparative analysis of hormonal peptides in more- and less-derived organisms should give us an idea of how the peptides might have evolved from the ancestral molecules. For example, insulin of the hagfish, the oldest extant vertebrate, was found to be identical to mammalian insulin in only 20 amino acids out of 53 (Peterson et al. 1974). However, subsequently Chan et al., (1984) reported highly divergent regions of the guinea pig preproinsulin in comparison with other mammals especially in the regions encoding the B- and A-chains.

Insulin has been isolated and characterized from several phylogenetically ancient actinopterygians (rayfinned fishes) including the gar, Lepisosteus spathula (Pollock et al., 1987), the bowfin, Amia calva (Conlon et al., 1991b), and the paddlefish, Polyodon spathula (Nguyen et al., 1994). In addition, insulin cDNAs have been reported from carp, Cyprinus carpio (Hahn et al., 1983).

The above mentioned studies led to a view that low molecular weight polypeptide hormones are not useful for constructing a phylogenetic tree (Conlon and Hicks, 1990; Agulleiro, 1995; Dores et al., 1996). Nevertheless, Dores et al. (1996) were able to construct a useful phylogenetic tree using proinsulin sequences based on the variable spacer region of proinsulin (C-peptide), which proved to have informative sites for phylogenetic analysis. Proinsulin sequences have been used to address several phylogenetic questions, such as the evolutionary distance between fresh water and marine teleosts (Hahn et al., 1983) or for the confirmation of the hypothesis that lungfish and amphibians share a common ancestor (Conlon et al., 1997). Also, proinsulin sequences allowed the confirmation of the phylogenetic position of the polypterids as being the most ancient living actinopterygians (Conlon et al., 1998).

In this study, we have cloned and sequenced the cDNAs of preproinsulin from four Osteoglossomorpha species: Osteoglossum bicirrhosum (arawana), Pantodon buchholzi (butterfly fish), Notopterus chitala (feather fin knife fish), Hiodon alosoides (goldeye), and proinsulin from Gnathonemus petersii (elephantnose). In addition, we have cloned and sequenced a preproinsulin cDNA from Catostomus commersoni (white sucker, as a representative of a more generalized teleost order, Cypriniformes).

The deduced amino acid sequences from the cDNAs of the different species are compared to each other as well as to those from other vertebrate species, to study the degree of conservation of the various domains and to provide a better understanding of the phylogenetic relationship among the osteoglossomorphs and between this group and other vertebrate species.

\section{Materials and methods}

\subsection{Animals}

Adults O. bicirrhosum (arawana), P. buchholzi (butterfly fish), G. petersii (elephantnose), and $N$. chitala (feather fin knife fish) were purchased from a local commercial aquarium in Toronto. Adult $H$. alosoides (goldeye) were fished from the Assinboine River near Winnipeg, and the viscera were obtained and frozen in liquid nitrogen. C. commersoni (white sucker) were trap-netted in the Lake Nipissing watershed (North Bay, Ont., Canada) and live specimens were obtained from local fish supplier. The live specimens were sacrificed by an overdose of $0.05 \%$ tricaine methanesulfonate (MS-222) in their holding water. Pancreatic tissues were excised, frozen in liquid nitrogen and kept at $-80^{\circ} \mathrm{C}$.

\subsection{RNA extraction, first-strand $c D N A$ synthesis and $R A C E$}

RNA was isolated from the frozen pancreatic tissues from the six species studied using TRIZOL reagent (Life Technologies, Grand Island, NY) according to manufacturer's directions. The RNA was reverse transcribed into cDNA using the Omniscript Reverse Transcriptase kit (QIAGEN, Mississauga, Ont., Canada) according to the manufacturer's protocol. The resulting first-strand cDNA was then used as a template for subsequent polymerase chain reactions (PCR). The partial insulin cDNAs were obtained using the following oligonucleotide primers: I 1, 5' GYNSCNCAGCACCTGTGCGGATCCCA $3{ }^{\prime}$ corresponding to the N-terminal of the B-chain and I 2, 5' RTTRCARTAYYNRTYCAGGTCGAAGATGTTGCA 3' corresponding to the C-terminal of the A-chain $(\mathrm{R}=\mathrm{A}+\mathrm{G}, \mathrm{S}=$ $\mathrm{G}+\mathrm{C}, \quad \mathrm{Y}=\mathrm{C}+\mathrm{T}, \quad \mathrm{N}=\mathrm{A}+\mathrm{C}+\mathrm{G}+\mathrm{T}) \quad$ (Fig. 1). Another set of primers was designed following the alignment of the initial partial insulin cDNA 
fragments from each different species under study; IR5, 5' CGAAGATGTTGCAGGGNCGGTGGCARCAYTGYTC 3' was used to obtain the 5' RACE (rapid amplification of cDNA ends) product and corresponded to the N-terminal of the A-chain. The other primer, which is used to obtain the $3^{\prime}$ RACE product, was IF3， 5' GCCCTGTACCTGGTGTGCGGCGAGAGRGGNTTYTTY $3^{\prime}$ and it corresponded to the C-terminal of the B-chain (Fig. 1). The primers were designed using the CODEHOP program (Rose et al., 1998, www.blocks.fhcrc.org/blocks/help/CODEHOP) and were synthesized by Sigma Genosys (Oakville, Canada). The RACE reaction was performed using the SMART RACE cDNA amplification kit (CLONTECH, Palo Alto, CA, USA) according to the manufacturer's instructions.

\subsection{Isolation of the preproinsulin $c D N A s$}

The 1st set of oligonucleotide primers were used in PCR reactions to obtain partial insulin cDNAs. The PCR product was cloned using pCR 2.1-TOPO vector (Invitrogen, Carlsbad, CA) according to the manufacturer's guidelines. Plasmid DNA from positive clones was then isolated using QIAprep Miniprep kit (QIAGEN, Mississauga, Ont., Canada) according to the manufacturer's guidelines. The isolated plasmid DNA was further analyzed using a restriction digest with EcoRI. Only the plasmids containing the insert were sequenced. The PCR RACE products were cloned and isolated using the same approach.

\subsection{Sequencing and identification of the cDNAs}

Two sequencing methods were used; automated and manual sequencing. For the automated sequencing, samples were sequenced either at the Core Molecular Biology Facility, York University (Ont., Canada) or at Cortec DNA Service Laboratories, Queen's University (Ont., Canada). The manual sequencing was performed using a T7 sequencing kit (Pharmacia Biotech, Baie d'Urfe, Quebec), and the radioisotope used in sequenc-

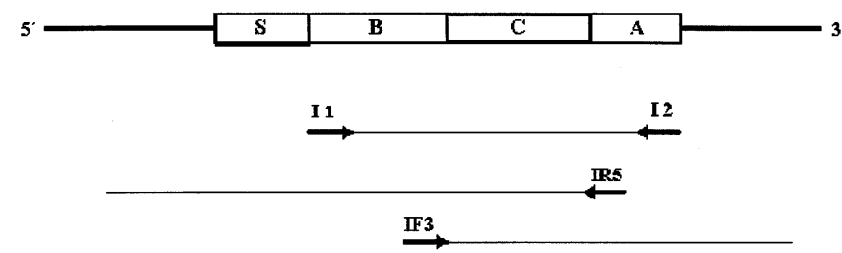

Fig. 1. Structure of the preproinsulin cDNA. The open box indicates the predicted open reading frame, which includes the coding region for the signal peptide (S), and the insulin B-chain (B), C-peptide (C) and A-chain (A). Thick lines indicate the $5^{\prime}$ and the $3^{\prime}$ untranslated regions. The bars with arrows indicate the position and the orientation of the oligonucleotide primers, whereas thin lines indicate the cDNA clones used for sequencing. ing $\left({ }^{35} \mathrm{~S}\right)$ was purchased from Amersham (Oakville. Ont.). The sequenced samples were run on a $6 \%$ polyacrylamide gels using Model S2 Sequencing gel Electrophoresis Apparatus (Canadian Life Technologies, GIBCO BRL, Burlington, Ontario). Manual sequencing was performed in two directions using an M13-reverse primer purchased from Pharmacia Biotech (Baie d'Urfe, Quebec), and the M13-forward primer (provided by the kit). The nucleotide sequences were independently aligned from several partial clones as well as from the RACE clones from each of the species studied, then were translated to the corresponding amino acid sequences, which were used in the phylogenetic analysis applying the PAUP 4.0b2 (phylogenetic analysis using parsimony; Swofford, 1999) program.

\section{Results}

Total pancreatic RNA was reverse transcribed to synthesize the cDNA, which was used as a template for the PCR reactions. The first set of primers (I1 and I2) were designed towards a conserved regions of the Band A-chains (Fig. 1), and PCR amplification gave a product of $\sim 264$ base pairs encoding the B-chain, $\mathrm{C}$-peptide and A-chain region. The sequence was confirmed by sequencing at least three clones from each species. The partial cDNAs were then aligned and a set of gene specific primers were designed (IR5 and IF3). IR5 primer was used for 5' RACE reaction, and produced a PCR product of $\sim 435$ base pairs, which included the $5^{\prime}$ untranslated region, and the coding region for the signal peptide, the B-chain, the $\mathrm{C}$-peptide and the $\mathrm{N}$-terminus of the A-chain. IF3 primer was used for 3' RACE, and a PCR fragment of 369 base pair was produced from the butterfly fish cDNA, which included the coding region for the $\mathrm{C}$-terminus of the B-chain, the C-peptide, the A-chain and the $3^{\prime}$ untranslated region ending with a poly A-tail. To confirm the sequences, five clones were sequenced for each PCR fragment from each species. The overlapping $5^{\prime}$ and $3^{\prime}$ RACE products yielded a sequence of 458 base pairs from the butterfly fish, as an example for the osteoglossomorphs (Fig. 1 and Fig. 2). As for the other species (excluding elephantnose), the overlapping region of the partial cDNAs sequences and the products of the $5^{\prime}$ RACE sequences confirmed the identity of the sequence. The open reading frame consisted of 110 amino acids in both the butterfly fish and the goldeye, 111 amino acids in both the arawana and the feather fin knife fish, and 108 amino acids in the white sucker. We obtained a partial sequence of 87 amino acids in the elephantnose (Figs. 3 and 4) (GenBank AF 199585-AF 199589 and AF 282408).

The comparison of the sequences to those from other species was used to identify the potential processing 


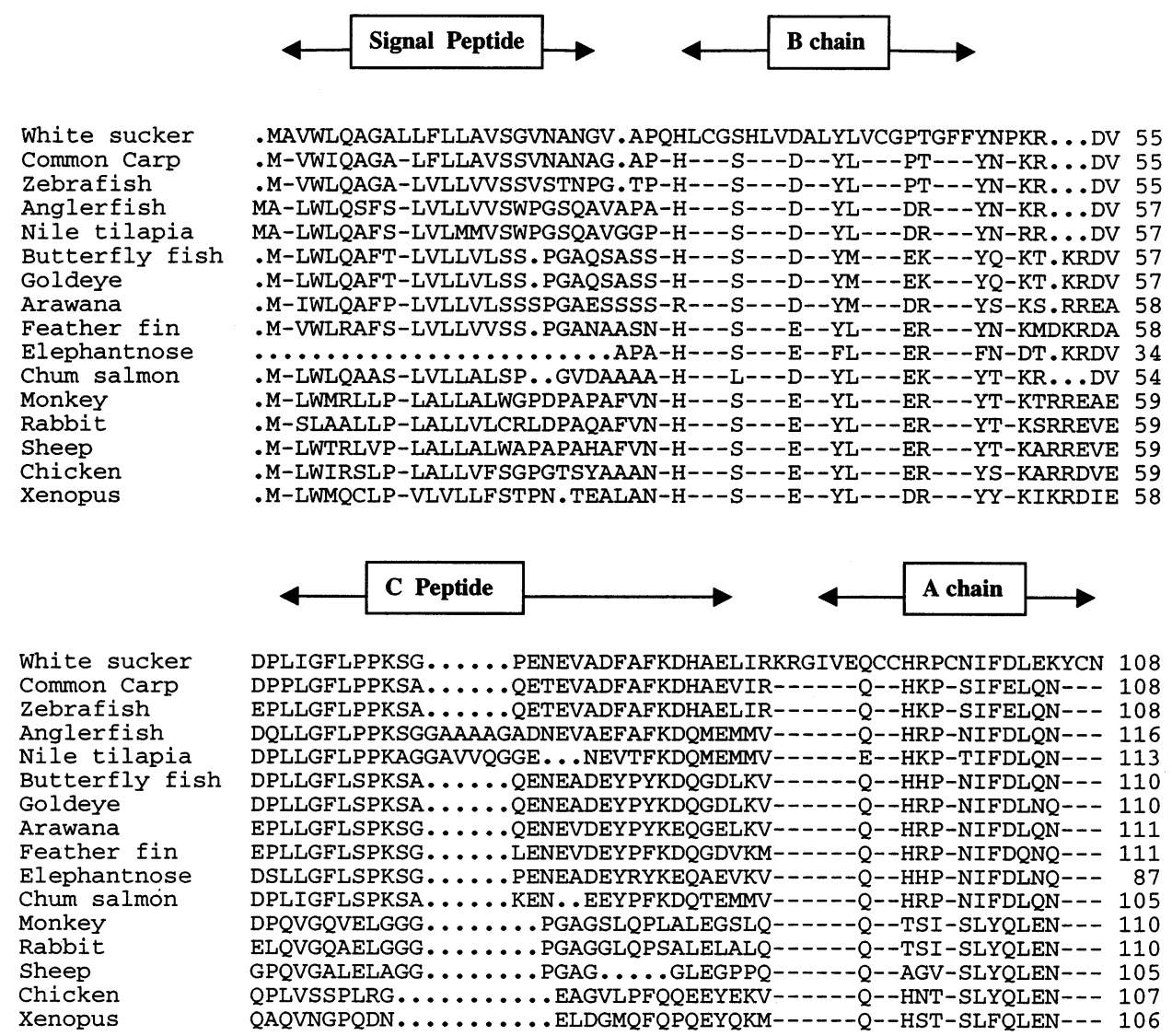

Fig. 4. Alignment of preproinsulin sequence from diverse vertebrate species. The amino acid sequence is numbered starting at the beginning of the signal peptide. Dots (.) indicate amino acid gaps in the sequence of different species, except in the elephantnose where the sequence encoding for the signal peptide was not determined. Dashes (-) indicate the identical residues.

B-18), with exception of B-17, A-13 and A-14. At these three positions, conserved substitutions were seen, with leucine at B-17 replaced by methionine in the butterfly fish, the arawana, and the goldeye, leucine at A-13 replaced by isoleucine, and tyrosine at A-14 replaced by phenylalanine in all of the species. The residues involved in the hexamer formation are believed to interact with the $\mathrm{Zn}^{2+}$ to form stable hexamers (Baker et al., 1988), and a substitution of one of these residues can effect the hexamer formation. In the case of the hagfish, a histidine was replaced by an aspartate at B-10, which prevented the formation of hexamers. The stabilization of the hexamer forms in the presence of high concentration of the $\mathrm{Zn}^{2+}$ was verified in several teleost insulins (Cutfield et al., 1986). This type of substitution was not observed in any of the osteoglossomorphs including the arawana, in which secretory granules of B-cells have a polymorphic crystalline core and are different from those observed in the other osteoglossomorphs (Al-Mahrouki and Youson, 1999). The N-terminal of the B-chain may also play a role in the hexamer formation (Conlon et al., 1991a) and this domain is weakly conserved in osteoglossomorphs. It is noteworthy that in arawana serine replaces alanine at
B-1, for this may explain the structural diversity of the secretory granules of the B-cells (Al-Mahrouki and Youson, 1999).

The known receptor-binding region at residues B-12, B-16, B23-26, A1-A5, A19, A21 were conserved in all the sequences, except for positions B-16 and B-26 in elephantnose. At these two positions are conservative substitutions, phenylalanine for tyrosine, but these substitutions might lead to reduced binding affinity (Conlon et al., 1991a). Several sites are involved in maintaining the receptor-binding conformation: glycine at B23, phenylalanine at B24, isoleucine at A2, valine at A3, and tyrosine at A19. These residues interact with the receptor and with other residues as well, for instance, leucine at B6, glycine at B8, leucine at B11, glutamate at B13 and phenylalanine at B25 (Conlon, 2000). These residues are conserved in the present sequences except for B13 where a conservative substitution (aspartate for glutamate) was observed in the arawana, goldeye, butterfly fish and white sucker. Generally, carbohydrates are low in teleost diets, and it was reported that teleosts do not use glucose efficiently as a general source of energy (Wilson, 1994). Parrizas et al. (1994) reported the presence of functional insulin recep- 
tors in tilapia skeletal muscle, which supports the earlier reports (King and Kahn, 1981; Mommsen and Plisetskya, 1991) on the important role of insulin in promoting somatic growth in teleosts. In general, however, the effects of insulin on metabolism and growth in fish are less differentiated than they are in mammals, perhaps due to the overlap in the function of insulin and insulin-like growth factor (Planas et al., 2000). Therefore, despite the conserved substitution of residues in the receptor-binding region of osteoglossomorph insulins, one must be cautious in extrapolating these data in a functional connotation. On the other hand, Wright et al. (2000) have recently emphasized that insulin plays an important role in glucose homeostasis in tilapia, at least at the level of the islet tissue. Since species variability in glucose metabolism may exist among the vast numbers of teleosts, bioassay of osteoglossomorph insulins are an essential future project.

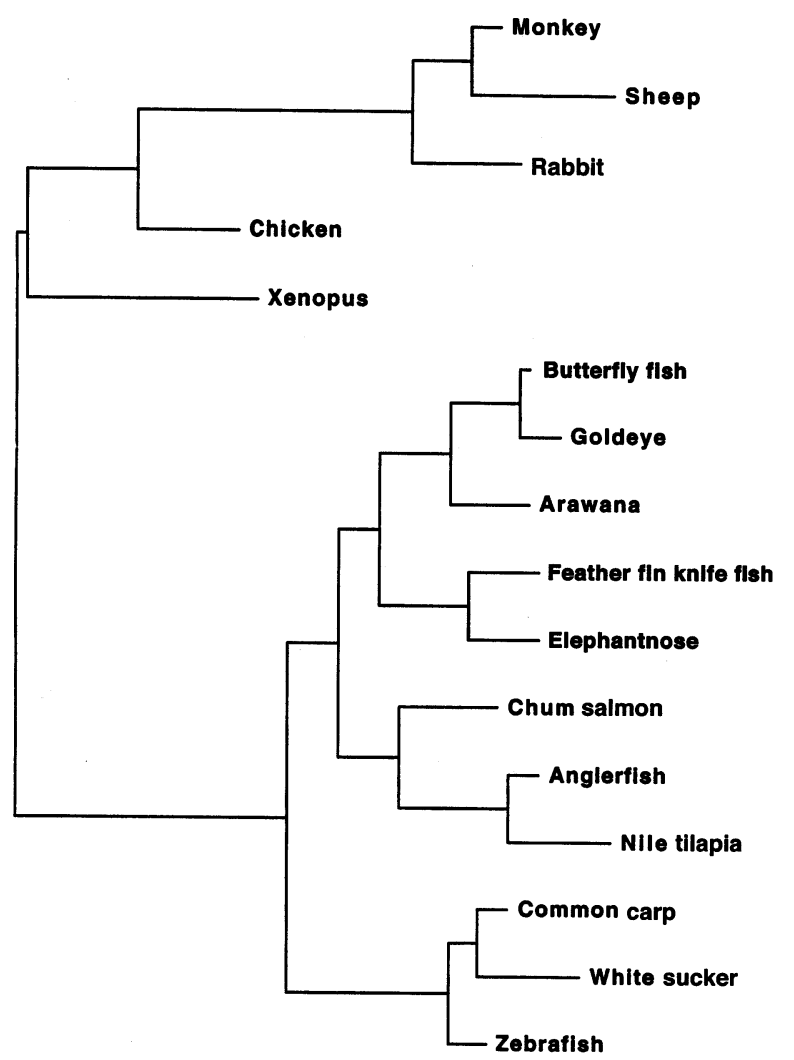

- 5 amino acid changes

Fig. 5. Phylogeny of preproinsulin sequences. Sequences from osteoglossomorphs and diverse vertebrate species (see Fig. 4) were analyzed by parsimony. Two similar trees were obtained, the only difference was in the relation of the white sucker to the commom carp/zebrafish. Branch length is proportional to the number of nucleotide replacement (i.e. resulting amino acid substitution) inferred by parsimony.
An extension to the $\mathrm{N}$-terminus of the B-chain was reported for insulins from some fish species, e.g. lungfish (Conlon et al., 1997), tuna, carp, anglerfish, cod (Shulinder et al., 1989) and lamprey (Plisetskaya et al., 1988). Extensions do not seem to effect the biological activities (Conlon et al., 1997), but their presence may be used to confirm monophylogenetic origins as in the case of holarctic and southern hemisphere lampreys (Conlon, 2000; Youson, 2000). In this study no extensions to the N-terminus of the B-chain was observed in any of the species under study; in the case of the osteoglossomorphs, it supports monophyletic origins.

\subsection{Phylogenetic analysis}

Hormonal peptides have been used by many to address phylogenetic questions in teleosts and in other vertebrate species. As explained in the introduction to the present investigation, insulin is one of these peptides (Conlon, 2000). Other GEP peptides, such as the sequences of glucagon-like-peptide, have been used to clarify the phylogenetic relationship of amphibians (Irwin and Sivarajah, 2000) and other vertebrates (Irwin et al., 1999). Also the preprosomatostatin sequence was used to confirm the close relationship of the lungfish and tetrapods (Trabucchi et al., 1999). Several studies have reported the usefulness of some polypeptide hormone precursors (Rubin and Dores, 1994; Urano et al., 1994; Grober et al., 1995; Rubin and Dores, 1995) in phylogenetic analysis, where the spacer region was often the informative character. Comparison of the deduced amino acid sequences of the preproinsulins of the present study to those from other fish and vertebrate species using maximum parsimony, revealed a grouping of the osteoglossomorphs, suggesting a monophyletic origin (same clade). Several reports, using the hard and soft anatomy support this conclusion ( $\mathrm{Li}$ and Wilson, 1996 and Zhang, 1998). Our comparative sequence analysis grouped the Notopteridae (e.g. feather fin knife fish) with the Momyridae (e.g. elephantnose), which supports the view of $\mathrm{Li}$ et al. (1997). The resulting relationship between the Pantodontidae (e.g. butterfly fish) and the Osteoglossidae (e.g. arawana) is supported by several reports (Lauder and Liem, 1983; Van Le et al., 1993). Greenwood (1973) grouped the Hiodontidae with the Notopteridae but the recent reassessment of the Hiodontidae concluded that it is a sister-group to all the osteoglossomorphs (Van Le et al., 1993; Li et al., 1997; Zhang, 1998). In our analysis the Hiodontidae (e.g. goldeye) was not grouped with the Notopteridae, but with the Pantodontidae and the Osteoglossidae, which in part agrees with other recent assessments. It has been suggested that the osteoglossomorphs are the most ancient living teleost fish (Nelson, 1973; Patterson and Rosen, 1977; Taverne, 1986), however, our phylogenetic analysis using insulin showed that osteoglosso- 
morphs are more generalized teleosts, which support the views of Arratia (1991) and O'Neill et al. (1998). As has been pointed out, the use of hormone-coding genes in phylogenetic analysis probably requires the sequence analysis of several polypeptides (Dores et al., 1996).

Our study has provided contributions in two dimensions. The results provide some assistance in resolving the debate over the position of the osteoglossomorphs within the teleosts, confirm their monophyletic origin, and provide a useful assessment of intergroup relationships. The second contribution is to comparative endocrinology analysis, where a description of the deduced peptide sequences attempts to identify the conservation of putative functional sites of insulin molecule in a key group of teleost with ancient lineage.

\section{Acknowledgements}

This study was supported by a grant from the Natural Sciences and Engineering Research Council of Canada to J.H. Youson.

\section{References}

Agulleiro, B., 1995. Phylogenetic approach to the vertebrate endocrine pancreas. Netherlands J. Zool. 45 (1-2), 124-128.

Al-Mahrouki, A.A., Youson, J.H., 1999. Ultrastructure and immunocytochemistry of the islet organ of Osteoglossomorpha (Teleostei). Gen. Comp. Endocrinol. 116, 409-421.

Alves-Gomes, J., Hopkins, C.D., 1997. Molecular insights into the phylogeney of Mormyriform fishes and the evolution of their electric organs. Brain Behav. Evol. 49, 324-351.

Arratia, G., 1991. The caudal skeleton of Jurassic teleosts: a phylogenetic analysis. In: Chang, M.M., Liu, Y.H., Zhang, G.R. (Eds.), Early Vertebrates and Related Problems of Evolutionary Biology. Science Press, Beijing, pp. 249-340.

Baker, E.N., Blundell, T.L., Cutfield, J.F., Cutfield, S.M., Dodson, E.J., Dodson, G.G., Hodgkin, D.M.C., Hubbard, R.E., Isacs, N.W., Reynolds, C.D., Sakabe, K., Sakabe, N., Vijayan, N.M., 1988. The structure of $2 \mathrm{Zn}$ pig insulin crystal at $1.5 \mathrm{~A}$ resolution. Philos. Trans. R. Soc. London, Ser. B 319, 369-456.

Chan, S.J., Episkopou, V., Zeitlin, S., Karathanasis, S.K., MacKrell, A., Steiner, D.F., Efstratiadis, A., 1984. Guinea pig preproinsulin gene: an evolutionary compromise? Proc. Natl. Acad. Sci. 81, $5046-5050$.

Conlon, J.M., 2000. Molecular evolution of insulin in non-mammalian vertebrates. Amer. Zool. 40, 200-212.

Conlon, J.M., Hicks, J.W., 1990. Isolation and ultrastructural characterization of insulin, glucagon and somatostatin from the turtle. Pseudemys scripta. Peptides 11, 461-466.

Conlon, J.M., Andrews, P.C., Thim, L., Moon, T.W., 1991a. The primary structure of glucagon-like peptide but not insulin has been conserved between the American eel, Anguilla rostrata and the European eel, Anguilla anguilla. Gen. Comp. Endocrinol. 82, $23-32$.

Conlon, J.M., Youson, J.H., Whittaker, J., 1991b. Structure and receptor-binding activity of insulin from a holostean fish, the bowfin (Amia calva). Biochem. J. 276, 261-264.

Conlon, J.M., Platz, J.E., Nielsen, P.F., Vaudry, H., Vallarino, M., 1997. Primary structure of insulin from the African lungfish, Protopterus annectens. Gen. Comp. Endocrinol. 107, 421-427.
Conlon, J.M., Fan, H., Fritzsch, B., 1998. Purification and structural characterization of insulin and glucagon from the bichir Polypterus senegalis (Actinopterygii: Polypteriformes). Gen. Comp. Endocrinol. 109, 86-93.

Cutfield, J.F., Cutfield, S.M., Carne, A., Emdin, S.O., Falkmer, S., 1986. The isolation, purification and amino-acid sequence of insulin from the teleost fish Cottus scorpius (daddy sculpin). Eur. J. Biochem. 158, 117-123.

Dores, R.M., Rubin, D.A., Quinn, T.W., 1996. Is it possible to construct phylogenetic trees using polypeptide hormone sequences? Gen. Comp. Endocrinol. 103, 1-12.

Greenwood, P.H., 1973. Interrelationships of osteoglossomorphs. In: Greenwood, P.H., Miles, R.S., Patterson, C. (Eds.), Interrelationships of Fishes. Academic Press, London, pp. 307-332.

Grober, M.S., Myers, T.R., Marchaterre, M.A., Bass, A.H., Myer, D.A., 1995. Structure, localization, and molecular phylogeny of a GnRH cDNA from a paracanthopterygian fish, the plainfin midshipman (Porichthys notatus). Gen. Comp. Endocrinol. 99, 8599.

Hahn, V., Winkler, J., Rapoport, T.A., Liebscher, D.H., Coutelle, C., Rosenthal, S., 1983. Carp preproinsulin cDNA sequence and evolution of insulin genes. Nucleic Acids Res. 11, 4541-4552.

Irwin, D.M., Huner, O., Youson, J.H., 1999. Lamprey proglucagon and the origin of glucagon-like peptides. Mol. Biol. Evol. 16 (11), $1548-1557$.

Irwin, D.M., Sivarajah, P., 2000. Proglucagon cDNAs from the leopard frog, Rana pipiens, encode two GLP-1-like peptides. Mol. Cell. Endocrinol. 162, 17-24.

King, G.L., Kahn, C.R., 1981. Non-parallel evolution of metabolic and growth-promoting functions of insulin. Nature 292, 644-646.

Kristensen, C., Kjeldsen, T., Wiberg, F.C., Schaffer, L., Hach, M., Havelund, S., Bass, J., Steiner, D.F., Andersen, A.S., 1997. Alanine scanning mutagenesis of insulin. J. Biol. Chem. 272, 12978 12983.

Lauder, G.V., Liem, K.F., 1983. The evolution and interrelationships of the actinopterygian fishes. Bulletin of the Museum of Comparative Zoology, Harvard University 150, pp. 95-197.

Li, G.Q., Wilson, M.V.H., 1996. Phylogeny of Osteoglossomorpha. In: Stiassny, M.L., Parenti, Johnson, G.D., (Eds.) 'Interrelationships of fishes' Academic Press, Inc., San Diego, California, pp. $163-174$.

Li, G.Q., Wilson, M.V.H., Grande, L., 1997. Review of Eohiodon (Teleostei: Osteoglossomorpha) from western North America, with a phylogenetic reassessment of Hiodontidae. J. Paleont. 71 (6), 1109-1124.

Mommsen, T.P., Plisetskya, E.M., 1991. Insulin in fishes and agnathans: History, structure, and metabolic regulation. Rev. Aquat. Sci. 4, 225-259.

Nelson, G.J., 1973. Notes on the structure and relationships of certain Cretaceous and Ecocene teleostean fishes. Am. Museum Novitates 2524, 31

Nguyen, T., Mommsen, T.P., Mims, S.D., Conlon, J.M., 1994. Characterization of insulins and pro-glucagon-derived peptides from a phylogenetically ancient fish, Polyodon spathula. Biochem. J. 300, 339-345.

O’Neill, D.F., Powell, J.F.F., Standen, E.M., Youson, J.H., Warby, C.M., Sherwood, N.M., 1998. Gondotropin-releasing hormone $(\mathrm{GnRH})$ in ancient teleosts, the bonytogue fishes: putative origin of salmon GnRH. Gen. Comp. Endocrinol. 112, 415-425.

Parrizas, M., Planas, J., Plisetskya, E.M., Gutierrez, J., 1994. Isulin binding and receptor tyrosine kinase activity in skeletal muscle of carnivorous and omnivorous fish. Am. J. Physiol. 266, R1944R1950.

Planas, J.V., Mendez, E., Banos, N., Capilla, E., Castillo, J., Navarro, I., Gutierrez, J., 2000. Fish insulin, IGF-I, and IGF-II receptors: a phylogenetic approach. Am. Zool. 40, 223-233. 
Patterson, C., Rosen, D.E., 1977. Review of ichthyodectiform and other Mesozoic teleost fishes and the theory and practice of classifying fossils. Bull. Am. Mus. Nat. Hist. 158, 81-172.

Peterson, J.D., Coulter, C.I., Steiner, D.F., Edmin, S.O., Falkmer, S., 1974. Structural and crystallographic observations on hagfish insulin. Nature Lond. 251, 239-240.

Plisetskaya, E.M., Pollock, H.G., Elliott, W.M., Youson, J.H., Andrews, P.C., 1988. Isolation and structure of lamprey (Petromyzon marinus) insulin. Gen. Comp. Endocrinol. 69 (1), 46-55.

Pollock, H.G., Kimmel, J.R., Hamilton, J.W., Rouse, J.B., Ebner, K.E., Lance, V., Rawitch, A.B., 1987. Isolation and structures of alligator gar (Lepisosteus spatula) insulin and pancreatic polypeptide. Gen. Comp. Endocrinol. 67, 375-382.

Rose, T.M., Schultz, E.R., Henikoff, J.G., Pietrokovski, S., McCallum, C.M., Henikoff, S., 1998. Consensus-degenerate hybrid oligonucleotide primers for amplification of distantly related sequences. Nucleic Acids Res. 26 (7), 1628-1635.

Rubin, D.A., Dores, R.M., 1994. Cloning of a growth hormone from a primitive bony fish and its phylogenetic relationships. Gen. Comp. Endocrinol. 95, 71-83.

Rubin, D.A., Dores, R.M., 1995. Obtaining a more resolute teleost growth hormone phylogeny by the introduction of gaps in sequence alignment. Mol. Phylogenet. Evol. 4, 129-138.

Shulinder, A.R., Bennett, C., Robinson, E.A., Roth, J., 1989. Isolation and characterization of two different insulins from an amphibian, Xenopus laevis. Endocrinology 125, 469-477.

Swofford, D.L., 1999. PAUP*. Phylogenetic Analysis Using Parsimony (* and Other Methods). Sinauer Associates, Sunderland, MA Version $4.0 \mathrm{~b} 2$.
Trabucchi, M., Tostivint, H., Lihrmann, I., Jegou, S., Vallarino, M., Vaudry, H., 1999. Molecular cloning of the cDNAs and distribution of the mRNAs encoding two somatostatin precursors in the African lungfish Protopterus annectens. J. Comp. Neurol. 410, $643-652$.

Taverne, L., 1986. L'evolution de l'antorbitaire et son incidence sur la phylogenie des teleosteens primitifs. Biol. Jb. Dodonaea 54, $142-$ 160.

Urano, A., Kubokawa, K., Hiraoka, S., 1994. Expression of the vasotocin and isotocin gene family in fish. In: Sherwood, N.M., Hew, C.L. (Eds.), Fish Physiology, Molecular Endocrinology of Fish, vol. XII. Academic Press, San Diego, pp. 102 134.

Van Le, H.L., Lecointre, G., Perasso, R., 1993. A 28S rRNA-based phylogeny of the Gnathostomes: first steps in the analysis of conflict and congruence with morphologically based cladograms. Molecular Phylogeny and Evolution 2 (1), 31-51.

Wilson, R.P., 1994. Utilization of dietary carbohydrate by fish. Aquaculture 124, 67-80.

Wright, J.R., Bonen, A., Conlon, M.J., Pohajdak, B., 2000. Glucose homeostasis in the teleost fish tilapia: insights from Brockmann body xenotransplanting studies. Am. Zool. 40, 234-245.

Youson, J.H., 2000. The agnathan enteropancreatic endocrine system: phylogenetic and ontogenetic histories, structure, and function. Am. Zool. 40, 179-199.

Zhang, J.Y., 1998. Morphology and phylogenetic relationships of dagger Kuntulunia (Teleostei: Osteoglossomorpha). J. Vert. Paleon. 18 (2), 280-300. 